\title{
An Assessment of the Predictors and Consequences of Workaholism using Hierarchical Models
}

\author{
Mariya Razzaghian ${ }^{1}$, Attaullah Shah ${ }^{2}$
}

\begin{abstract}
Workaholism is one of the least researched phenomena in organizational behavior in $\mathrm{Pa}$ kistan. Since it is considered akin to other forms of addiction, this study attempted to define, measure and reinforce the notion of workaholism within the addiction framework. This was done in order to address some of the gaps in previous researches. Using the trait theory and social learning paradigm, big 5 personality traits and social contagion were hypothesized as the predictors of workaholism. Similarly, drawing from the literature on well-being, counterproductive work behavior was postulated as a consequence of workaholism having a negative impact on employee well-being in the form of job burnout. A multi-stage sampling approach was employed. The analysis sample constituted a total of 1467 faculty members serving in the higher education institutions all over Pakistan. The results revealed that the traits of conscientiousness, neuroticism, and extraversion, as well as social contagion, were significant predictors of workaholism. At the same time, workaholism was found to be a significant predictor of counterproductive work behavior and, via the indirect effect, of job burnout. This lent support to the addiction framework. One of the major contributions of this study included the use of formative second-order hierarchical models.
\end{abstract}

Keywords: Workaholism, well-being, aggression, hierarchical models, structural equation modeling, partial least squares.

\section{Introduction}

In today's world, the work sphere comprises a major area of life in which people are constantly striving to attain prestige, recognition, and self-esteem. In addition, the nature of careers is changing due to social comparisons, mobility, and self-development. This further encourages people to work exceedingly hard in order to make meaningful organizational contributions; as well as to eventually climb to the top of

1 PhD Scholar, Institute of Management Sciences, Peshawar, Pakistan.

E-mail:moorazz@hotmail.com

2 Associate Professor, Institute of Management Sciences, Peshawar, Pakistan.

E-mail:attashah15@hotmail.com

\begin{tabular}{ll} 
ARTICLE HISTORY & \\
6 Aug, 2018 Submission Received & 8 Sep, 2018 First Review \\
\hline 10 Oct, 2018 Second Review & 22 Nov, 2018 Third Review \\
\hline 2 Dec, 2018 Accepted &
\end{tabular}


the proverbial corporate ladder. These organizational changes, in turn, have an impact on individuals' jobs as well as their well-being, health, and safety. In the race to achieve productivity and promotion, the organizations expose their employees to long working hours. On the surface, a hardworking employee may look appealing. In reality, if this notion of hard work in the form of long hours resulted in workaholism, could lead to addiction. The motivation to work hard for excessively long hours not only stems from a strong inner force to succeed but also from certain external factors that are contextual in nature, e.g., financial problems, organizational culture, and the drive for career advancement (Taris, Schaufeli \& Verhoeven, 2005). Therefore, there is a growing interest among the researchers and practitioners in the study of workaholism due to the myriad conceptualizations that are associated with its study.

However, it is regrettable that to-date the conceptualization of working long hours as a national level phenomenon, in the literature, is mainly limited to western cultures. However, Asian countries like Japan or China have also been able to capture attention (Hu et al., 2014) primarily due to the concept of Karoshi- a Japanese term signifying death from over-work; that became a social issue and elicited attention (Horne, 1998). Since the occurrence of workaholism has increased all over the world (Ugwu, 2011), there are obvious grey areas that could be covered for a fuller understanding of workaholism. The present research is, in fact, an effort to extend a fine-grained understanding of this concept in Pakistan by presenting a model that involves great detail regarding this construct.

The present study embraces workaholism as an addiction to one's work (Porter, 1996) classifying it as the bad type of working hard (Shimazu \& Schaufeli, 2009). Formerly, addiction was mostly used in relation to the uncontrollable and excessive use of chemicals that were psychoactive (Andreassen et al., 2013). For the past two decades, the focus on the non-chemical psychological and behavioral addictions (Griffiths, 1996) has increased. Examples of such addictions include the use of Facebook, video games, exercise, and study addiction to name a few. Workaholism, too, was declared as a non-chemical psychological addiction (Andreassen, Hetland \& Pallesen, 2010) that is persistent in nature and is characterized by a desire to continue the activity without any voluntary control over it. Similar to other addictions, it also has detrimental effects on well-being and could also result in aggression (Walker, 1989).

It has been observed that the best jobs in the market have become more and more challenging with regard to effort and time and this dilemma has been on a constant rise. The faculty members employed in academia are no exception to this observed trend (Jacobs \& Winslow, 2004a). The nature and meaning of higher education have become institutionalized and are globally applicable. This also signifies that university category or the faculty member titles were immaterial. Rather they "maybe locally 
shaped in minor ways but at the same time have a very substantial historical and global standing. Universities and colleges together with their disciplinary fields and academic roles are defined, measured, and instantiated in essentially every country in explicitly global terms" (Meyer, Ramirez, Frank \& Schofer, 2007, p. 187-188).

Unlike other high-profile occupations, professors in academia work for long hours but lesser remuneration. Therefore, it comes as no surprise that they consider their jobs to be never-ending. To top it all off, for faculty on tenure or those aspiring to achieve tenure, a more rigorous investment in time is required of them. However, research on faculty working-time is scant (Jacobs \& Winslow, 2004b). An average workweek for full-time faculty in English speaking countries was found to be 50.1 hours, 49.7 hours in Asia, 48.3 hours in Western Europe, and 45.4 hours in Latin America (Bentley \& Kyvik, 2011). Long workweeks are experienced by academic faculty irrespective of title (assistant, associate and full professor) and type of the institution (research, liberal arts etcetera) (Jacobs, 2004).

This study focuses on the individual difference factors and the contextual factors to explain how they may play a role in predicting workaholism within the academic faculty. The trait theory and social learning paradigm were the primary triggers of predicting workaholism from personality traits of an individual and social contagion, respectively. On the other hand, the aggression and well-being literature lead to the identification of the consequences of workaholism in the form of counterproductive work behavior and job burnout, respectively.

\section{Literature Review}

\subsection{Workaholism}

The term workaholism was first identified by Oates (1971, p. 11) who defined it as "the compulsion or the uncontrollable need to work incessantly". In his seminal work, he repeatedly drew parallels between workaholism and alcoholism. It was also explained that the drive to work ceaselessly gets so exaggerated that it ultimately poses a risk to the health, personal happiness, interpersonal relationships, and social functioning of the workaholics. Since its inception, researchers have defined workaholism from different perspectives, for example, an addiction, a behavior pattern, a set of attitudes towards working or a syndrome (Tziner \& Tanami, 2013).

Different theories have proven useful in explaining the manifestations of workaholic tendencies, however, the primary focus of this study has been around the social learning paradigm and trait theory. The social learning paradigm assumes that workaholism occurs due to role modeling and the individuals may want to imitate 
those they consider as influential. This paradigm can be expanded to state that a behavioral contagion involves the initiator and the imitator and is characterized by four conditions (Redl, 1949). First, the imitator feels a strong impulse towards a need, but the conscience pressurizes the imitator to ignore the impulse. Second, both the impulse and the pressure exerted by the conscience on the imitator gets stronger. Third, the initiator also expresses similar need(s). Finally, the initiator openly acts to fulfill his need (Williamson \& Cable, 2003).

Similarly, trait theory has also provided valuable insights into understanding workaholism. This theory can be further subdivided into the trait-specific approach and a broader personality approach. According to the trait-specific approach, certain traits like perfectionism, compulsiveness, and rigidity are responsible for causing workaholism in individuals (Mudrack, 2004). Whereas, broader personality approach defined workaholism on the basis of higher order personality traits like conscientiousness (Clark, Livesley, Schroeder \& Irish, 1996) and neuroticism (Burke, Matthiesen \& Pallesen, 2006).

Some of the other approaches elucidating workaholism include obsessive-compulsive personality disorder (Naughton, 1987), mood-as-input model (Benabou \& Tirole, 2004), addiction theory (Porter, 1996), operant learning theory (McMillan, O'Driscoll \& Burke, 2003), cognitive theories (Ellis, 1994), and the family systems theory (Robinson, 2001).

\subsection{Predictors of workaholism}

\subsubsection{Big 5 personality traits}

A factor that has been found to contribute to both chemical and behavioral addictions is personality (Grant, Potenza, Weinstein \& Gorelick, 2010). The big 5 personality traits were hypothesized to be a predictor of workaholism in this study. A personality trait is a durable disposition to behave in a particular way in different situations (Epstein, 1994). The evidence to use personality theories while studying workaholism is also supported by Eysenck (1997) and McMillan et al. (2003) who declared that it can be explained by trait and personality theories. Previous studies have also indicated that certain personality factors (e.g., extraversion and conscientiousness) may contribute to the work culture a person determines for him/herself (Bakker, Van der Zee, Lewig \& Dollard, 2006).

The big 5 personality traits include agreeableness, conscientiousness, extraversion, neuroticism, and openness to experience. Individuals possessing the trait of agreeableness are characterized by feelings of empathy and selflessness. They have a caring and nurturing attitude towards others. Due to this cooperative nature, such 
individuals usually do not refuse to do any extra task that would please others and hence in this process, they overexert themselves (Siebert \& Kraimer, 2001).

H1a: Agreeableness will positively impact workaholism.

The trait of conscientiousness is associated with persistency. Individuals who are high on this trait are self-disciplined, achievement-oriented, dutiful and competent (McCrae \& Costa, 1986). This trait was found to have the strongest relationship with other behavioral addictions including study addiction (Andreassen et al., 2013). The previous study by Andreassen et al. (2010) has shown a positive association between conscientiousness and workaholism. Bruck and Allen (2003) have shown that individuals possessing the trait of conscientiousness are organized, punctual and strongwilled people. They may immerse themselves in work as a means of achieving a sense of productivity and increased efficiency (Glaser, 1976).

H1b: Conscientiousness will positively impact workaholism.

Individuals possessing the trait of extraversion are called extroverts and are characterized by those individuals who are self-confident and tend to be dominant. Extroverts have a lot of positive emotions and energy because of which they prefer to have frequent and intense interactions with the people around them (Goldberg, 1990). Since extroverts look out for stimulation (Eysenck, 1967), this trait is believed to be commonly associated with addictions (Hill, Shen, Lowers \& Locke, 2000). Extroverts may also engage in various behavioral addictions as a way to express their social needs and tendencies (Ross et al., 2009), and also to express their specific identities or the identity of their groups or departments. It is possible that they indulge in excessive work in the form of workaholism in order to maintain their dominance over their colleagues. Also, they are individuals who have a lot of energy, making it possible that they may utilize their energy by engaging in workaholism without them being aware of doing so. Hospitability is another trait of extraversion (John, 1990). This highlights the likelihood that such individuals may end up doing more work themselves rather than asking for help from their colleagues on the job. In previous studies (for example, Andreassen, Torsheim, Brunborg \& Pallesen, 2012; Bianchi $\&$ Phillips, 2005) an association between this trait and other behavioral addictions namely, Facebook, mobile phone, exercise, and compulsive buying addiction was observed. Aziz and Tronzo (2011) had also hypothesized that extraversion will be positively related to workaholism.

H1c: Extraversion will positively impact workaholism.

The trait of neuroticism pertains to how emotionally stable or in the case of a lack of stability how neurotic an individual is (Costa \& McCrae, 1991). High neurot- 
icism is associated with a distressful mind (Bruck \& Allen, 2003). Such individuals usually exhibit fearfulness, irritability, decline in self-esteem, social anxiety, and poor inhibition of impulses and feelings of helplessness (Costa \& McCrae, 1987). Such individuals also tend to have anger outbursts, worry more and get sad often. Eysenck (1997) established that extraversion and neuroticism are causally related to biological factors (genetic factors) which, in turn, lead to addictive work behavior. Since neurotics develop feelings of social anxiety easily, they may usually want to work on things alone (Tsai et al., 2009). Andreassen et al. (2013) found a positive association between study addiction and neuroticism. Building from this work and the discussion undertaken, it can be predicted that neuroticism may be involved in predicting workaholism due to the neurotics' personal insecurity, fear of failure and/or strict work ethics (de Vries, 2005).

H1d: Neuroticism will positively impact workaholism.

The fifth factor, openness to experience is associated with intellect and autonomy because these individuals will always try to learn something positive even from experiencing any stressful situation (Costa \& McCrae, 1992). These individuals are also believed to be more flexible and imaginative even when they experience distressing situations (Watson \& Hubbard, 1996). The trait of openness has also been linked with Facebook and mobile addictions (Correa, Hinsley \& de Zuniga, 2010). This trait could also be a possible predictor of workaholism because individuals open to experience find work as an opportunity to learn, to be imaginative and curious as well as to widen their horizons to explore new opportunities (Gjerde \& Cardilla. 2009).

H1e: Openness to experience will positively impact workaholism.

\subsubsection{Social contagion}

The understanding of the term social contagion has evolved over time to include a wide range of social phenomena that spread across networks. Such phenomena included fads, adoption of new technology or even political opinions (Ugander, Backstrom, Marlow \& Kleinberg, 2011). Over a century ago definitions of social contagion came to surface. Le Bon (1903) was among the first few to define the term social contagion in his book on crowd behavior. According to him, when in a crowd, the emotions and behaviors of individuals can get contagious to the level where an individual will sacrifice his own interest in favor of the interest of the group. In the same way, Redl (1949) described social contagion as the transfer of behavior whereby contagious behaviors are automatically absorbed. In line with this, Latane (2000) labeled the psychological phenomenon explaining the diffusion of longer work hours within an industry as social contagion. He also proposed that when individuals interact with 
significant others, they have a tendency to relate to them.

In 1954, Festinger had proposed a theory of social comparison whereby it was hypothesized that human beings have a drive to evaluate their opinions and abilities. The work behavior of a person is directly proportional to his opinions and beliefs about his existing work situation and his capabilities of performance in that situation. Individuals have a continuous desire to learn about the self through comparison with others from time to time (Gibbons \& Buunk, 1999).

According to social learning paradigm (McMillan et al., 2003), social contagion may occur when people change their behaviors, for example, work hours, as a consequence of social interaction with others (Brett \& Stroh, 2003). In other words, workaholism can be a result of role modeling which refers to imitating others who are considered influential, for instance, one's seniors or colleagues. Although the social learning paradigm is quite popular in explaining workaholism, so far empirically this has not been tested.

The above discussion can be summed up to conclude that a possible cause of workaholism can also be embedded in social comparisons with each other on the job. A climate of competitiveness that arises due to this social contagion can influence the employees and make them work incessantly.

H2: Social contagion will positively impact workaholism.

\subsection{Outcomes of workaholism}

\subsubsection{Counterproductive work behavior (CWB)}

Counterproductive Work Behavior is defined as any behavior that leads to the violation of organizational norms and is detrimental either to the organization or its members or both (Robinson \& Bennett, 1995). The research on CWB shows that these acts are precipitated by conditions and situations in the work environment. Although some individuals are more inclined to experience negative emotions and engage in CWB, there is some provocation that triggers a reaction (Spector, Fox, Domagalski, 2006).

According to theories of emotion regulation and coping, when individuals experience stressful situations they tend to cope with this stress by engaging in CWBs. This is done with the aim of reducing the negative emotions experienced as a result of stress (Penney \& Spector, 2007). Therefore, CWB becomes a coping mechanism for these individuals.

Workaholism is believed to have negative consequences. Balducci, Cecchin, Frac- 
caroli, and Schaufeli (2012) have argued that workaholism and workplace aggression have a strong connection due to the reason that workaholics are high on emotional reactivity and low on self-regulation (Barling, Dupre, \& Kelloway, 2009). Supporters of different models of aggression state that there are certain critical inner states in an individual which can trigger aggression in the workplace (Neuman \& Baron, 2005). Since workaholics are low on subjective well-being (Schaufeli, Bakker, Van der Heijden \& Prins, 2009b), they are more vulnerable to experience those critical inner states which propel aggression in the workplace. In the study by Shimazu, Schaufeli, and Taris (2010), it was revealed that workaholism is positively related to outward transmission of negative moods to others.

H3: Workaholism will positively impact counterproductive work behavior.

\subsubsection{Job burnout (As the mediator)}

Job burnout is an individual level reaction to stress because it is believed to develop as a reaction to job stressors (Cordes \& Dougherty, 1993). It has been agreed upon that an individual's own over-commitment to too much frustrating work can cause work-related burnout (Freudenberger, 1983). The development of burnout is a result of stressors faced on the job. Several theoretical approaches have been used to explain burnout and in the 1990s conservation of resources (COR) was adapted to understand the process of burnout in organizational settings (Hobfoll \& Shirom, 2001). The basic tenet of COR theory is that people have an inherent as well as a learned drive to create, foster, conserve, and protect the quality and quantity of their resources. According to Hobfoll (1989, p. 516), resources are "those objects, personal characteristics, conditions, or energies that are valued by the individual". They may be provided to employees by organizations (e.g., logistical, financial, or social support) or they may be a result of some individual difference such as the propensity to work in an organized manner and maintain calm conduct. According to COR theory, three conditions can lead to stress: (1) when individuals' key resources are threatened with the loss (2) when resources are lost or (3) when individuals fail to gain resources following significant resource investment. Employees may invest available resources to obtain additional resources. Therefore, it can be said that whenever the individual's resources are threatened due to various stressors or demands on the job, it becomes a source of strain. This eventually leads to emotional and/or physical strain.

\subsubsection{Relationship between workaholism and job burnout}

The COR theory can be extended to explain the relationship between workaholism and job burnout. Maslach (1986) considered workaholism as a root cause of burnout. Since workaholics spend most of their time at work, they usually don't 
get enough time to unwind from their work-related efforts (Schaufeli, Shimazu \& Taris, 2009a). Also, as one becomes more and more absorbed in work, a course of workaholism may unfold (Sussman, 2012). This explains why workaholics are often emotionally or cognitively exhausted (Taris et al., 2005) and burned out as they spend too much energy at work, which they cannot counterbalance properly (Schaufeli et al., 2009a). Also, as their thoughts are consistently engaged in thinking about their work this may trigger emotional distress in them. Therefore, increased levels of psychological distress have been reported by workaholics (Taris, et al., 2005). Several empirical studies reported a positive association between workaholism and burnout (for example, Burke, 2008), signifying that workaholics are at a greater risk for burnout (McMillan \& O’Driscoll, 2004).

H4: Workaholism will positively impact job burnout.

\subsubsection{Relationship between job burnout and counterproductive work behavior}

Most models of CWB describe an emotion-centered process wherein the perception of negative workplace events trigger the experience of negative emotions (e.g., anger and frustration) that in turn energize a CWB response (Spector \& Fox, 2005). The primary triggers of burnout are believed to be within the environment of an individual (Buhler \& Land, 2003). It is believed that burnout is common in all organizations (Golembiewski, Boudreau, Sun \& Luo, 1998) but organizations that have a tenure system are significantly more affected by it (Maslach, Jackson \& Leiter, 1996). On the other hand, literature has described CWB as a behavioral reaction to stressful work scenarios (Spector \& Fox, 2005) whereby they are considered as harmful and inconsistent with the personal goals (Lazarus, 1991). This is done with the intention to reduce or even remove the negative emotional state they feel themselves to be in (Spector \& Fox, 2005) because they view CWBs as a way to restore equity between the negative emotions and their work behavior (Schaufeli, Taris \& Bakker, 2006). Penney, Hunter, and Perry (2011) have highlighted that there is a dearth of studies applying COR theory in the prediction of behavioral strains such as CWB. However, one study by Krischer, Penney, and Hunter (2010) has shown that those employees who reverted to CWB, experienced less emotional exhaustion as compared to those who did not. Therefore, it can be said that employees may use CWB to conserve resources and reduce exhaustion and psychological strain. This research applies the COR theory in the association between job burnout and CWB. It argues that since burnout typically follows from a process of slow depletion of resources, without counterbalancing resource gain or replenishment, thus, there are chances that employees may engage in CWB.

H5: Job burnout will positively impact CWB. 
2.3.2.3. Job burnout as a mediator of the relation between workaholism and CWB

Synthesizing from the above discussion, it is evident that workaholism can be considered as the bad type of working hard (Shimazu \& Schaufeli, 2009) which is addictive and therefore, can have negative ramifications. The COR theory, aptly, paints how workaholism can be linked to both aggression and poor well-being. Since it has been established from the literature that workaholism could lead to job burnout (H4), which could, in turn lead to CWB (H5). Therefore, the current study proposed that job burnout mediates the relationship between workaholism and CWB.

H6: Job burnout will significantly mediate the relationship between workaholism and CWB.

\section{Research Methodology}

\subsection{Sample}

All full-time faculty members serving in the higher education institutions all over Pakistan served as the target population for this quantitative study. A total of 162 universities with a total faculty count of 36989 teachers constituted as the sampling frame.

\subsection{Sampling technique}

A multi-stage sampling technique was adopted to get a representative sample of the entire population. In the first stage, a total of 7 unequal clusters were formed on the basis of geographical regions, out of which 4 clusters were selected in order to achieve maximum variance. These 4 clusters represented $91 \%$ of the population. Next, a sample of 60 universities was drawn using $n=N /\left(1+N^{*} E^{2}\right)$ (Yamane, 1967). Universities from every cluster were randomly drawn according to their proportion in each. Furthermore, a representative sample of respondents was separately obtained from every cluster using the same formula.

Thus, a total of 1800 questionnaires were distributed and 1497 questionnaires were received, making the response rate of the study to be $83 \%$. After the scrutiny, 1467 questionnaires were left for further data screening and analysis. Prior to final testing, the data were checked for missing cases, skewness, and kurtosis.

\subsection{Demographics}

The participants of the study comprised of $51 \%$ males and $49 \%$ females. Among these participants, 50\% were lecturers, 29\% were assistant professors, $11 \%$ associate professors, and $10 \%$ full professors. Of these participants, $16 \%$ were associated with their current institution for less than one year, $36 \%$ associated for one to five years, 
$29 \%$ had a five to ten years tenure in the current institution, whereas, $19 \%$ were associated with their institution for more than ten years.

\subsection{Measures}

\subsubsection{Workaholism}

Workaholism was measured through Robinson's (1999) five-factor model called the Work Addiction Risk Test (WART) that is composed of 25 items. It included: compulsive tendencies, control, impaired communication/self-absorption, inability to delegate, and self-worth. The responses ranged on a 5-point Likert scale $(1=$ never true, 5 = always true).

\subsubsection{Counterproductive work behavior}

CWB was measured using Bennett and Robinson's (2000) scale that has 19 items. This scale operationalizes CWB along two dimensions: organizational and interpersonal deviance. The responses ranged on a 5-point Likert scale $(1=$ never to 5 = very frequently).

\subsubsection{Big 5 personality traits}

The Big 5 personality was measured using the Big Five Inventory (BFI- 10) constructed by John, Donahue, and Kentle (1991). It consists of 10 items and the responses ranged on a 5 -point Likert scale $(1=$ strongly disagree and $5=$ strongly agree $)$.

\subsubsection{Social Contagion}

Social contagion was measured with the Iowa Netherlands Comparison Orientation Measure (INCOM) developed by Gibbons and Buunk (1999). INCOM operationalizes social contagion along two dimensions: comparison of abilities and comparison of opinions. It consists of 11 items and the responses ranged on a 5-point Likert scale $(1=$ strongly disagree and 5 = strongly agree).

\subsubsection{Job burnout}

Job burnout was measured through the Maslach Burnout Inventory- MBI (Maslach \& Jackson, 1981). MBI operationalizes job burnout along three dimensions: emotional exhaustion, depersonalization, and reduced personal accomplishments. It consists of 22 items and the responses ranged on a 5-point Likert scale ( $1=$ strongly disagree, 5 = strongly agree). 


\subsection{Data analysis technique}

The data was analyzed through partial least squares based structural equation modeling (PLS-SEM), a 2G technique, using SMARTPLS.

\section{Analysis and Results}

\subsection{Measurement model}

The present research takes into account guidelines by Jarvis, Mackenzie, and Podsakoff (2003) and Mackenzie, Podsakoff, and Jarvis (2005) to distinguish between the formative and reflective variables of the study in order to avoid measurement model misspecifications. With the exception of one, all independent and dependent variables of the study were reflective-formative hierarchical models with two layers.

The assessment of outer or measurement models, that are reflective, start with the factor analysis which shows the factor loadings of each indicator. The suggested loading of each indicator should be 0.7 or above (Hair, Ringle \& Sarstedt, 2011). Based on this cut-off score, the following indicators were deleted: 3 items from job burnout - exhaustion and 1 item from job burnout - depersonalization. 4 items from CWB - organizational. 3 items from workaholism - control, 4 items from workaholism - compulsive tendencies and 2 items from workaholism - communication. After deletion, PLS algorithm was re-run along with bootstrapping at 5000 subsamples.

This was followed by the verification of internal consistency reliability, convergent validity and discriminant validity (Henseler, Ringle \& Sinkovics, 2009). Internal consistency reliability was measured through composite reliability (CR) developed by Werts, Linn, and Joreskog (1974). It was estimated using the formula:

$$
\mathrm{CR}=\left(\sum \chi_{\mathrm{i}}\right)^{2} \operatorname{var} \mathrm{F} /\left(\sum \chi_{\mathrm{i}}\right)^{2} \operatorname{var} \mathrm{F}+\sum \theta_{\mathrm{ii}} .
$$

Where: $\lambda \mathrm{i}$ is the outer loading, $\mathrm{F}$ is the factor variance and, $\Theta \mathrm{ii}$ is the error variance. The cut-off score for composite CR is $\geq 0.7$ (Hair et al., 2011). As shown in Table 1, all the composite reliabilities for this study were well within the threshold of 0.7 indicating good internal consistency reliability of each latent factor.

Convergent validity was checked through Average Variance Extracted (AVE). AVE was calculated using the formula (Fornell \& Larcker, 1981):

$A V E=\left(\sum \chi_{i^{2}}\right) \operatorname{var} F /\left(\sum \chi_{i^{2}}\right) \operatorname{var} F+\sum \theta$ ii.

Where $\lambda \mathrm{i}$ is the outer loading, $\mathrm{F}$ is factor variance and $\mathrm{Oii}$ is error variance. The AVE is the grand mean value of the squared loadings of a set of indicators and is 
equivalent to the communality of a construct (Hair et al., 2011). AVE of 0.5 shows that the construct explains more than half (50\%) of the variance of its indicators (Chin 2010). The AVEs of all latent factors were above 0.5 , pointing to a good convergent

Table 1: Composite Reliabilities and Average Variance Extracted

\begin{tabular}{|c|c|c|c|}
\hline Latent Variables & Factors & $\begin{array}{c}\text { Composite Reliabili- } \\
\text { ty }(\mathrm{CR})\end{array}$ & $\begin{array}{c}\text { Average Variance } \\
\text { Extracted (AVE) }\end{array}$ \\
\hline \multirow{2}{*}{$\begin{array}{l}\text { Counterproductive } \\
\text { Work Behaviour }\end{array}$} & Interpersonal & 0.89 & 0.54 \\
\hline & Organizational & 0.86 & 0.52 \\
\hline \multirow[t]{3}{*}{ Job Burnout } & Exhaustion & 0.77 & 0.53 \\
\hline & Depersonalization & 0.77 & 0.54 \\
\hline & Accomplishments & 0.85 & 0.50 \\
\hline \multirow[t]{5}{*}{ Big 5 Personality Traits } & Agreeableness & 0.87 & 0.78 \\
\hline & Conscientiousness & 0.83 & 0.72 \\
\hline & Extraversion & 0.88 & 0.79 \\
\hline & Neuroticism & 0.84 & 0.73 \\
\hline & Openness & 0.84 & 0.72 \\
\hline \multirow[t]{2}{*}{ Social Contagion } & Abilities & 0.79 & 0.57 \\
\hline & Opinion & 0.76 & 0.52 \\
\hline \multirow[t]{5}{*}{ Workaholism } & Delegate & 1 & 1 \\
\hline & Control & 0.81 & 0.53 \\
\hline & Compulsive & 0.83 & 0.50 \\
\hline & Worth & 0.72 & 0.56 \\
\hline & Communication & 0.78 & 0.54 \\
\hline
\end{tabular}

Note: CR $\geq 0.70 ; A V E \geq 0.5$

validity as presented in Table 1 .

The model was also checked for discriminant validity through the Hetrotriat-Monotriat (HTMT) ratio. A value of HTMT above 0.90 (Gold, Malhotra \& Segars, 2001) indicates a lack of discriminant validity. All the HTMT values for the latent variables were below the threshold level of 0.90 . This was an indication of the establishment of discriminant validity of the outer model. It was followed by a complete bootstrap at 5000 samples (Hair et al., 2011) to check the HTMT inference criterion. Here any value that is equal to or greater than 1.0 in the upper level of the confidence interval, which is $97.5 \%$, is checked. In order words, the null hypothesis $\left(\mathrm{H}_{0}\right.$ : HTMT $\geq 1)$ is tested against the alternate hypothesis $\left(\mathrm{H}_{1}:\right.$ HTMT $\left.<1\right)$. All the reflective indicators were falling in the upper threshold limit (that is, below 1). 


\subsection{Hierarchical component model}

Each higher order (formative) component was initially tested for collinearity because high levels of correlation between formative indicators can produce biased results (Hair at al., 2011). The collinearity was checked through the variance inflation factor (VIF). The suggested threshold value of VIF is $<5$ (Hair et al. 2011). All VIF values were well below the threshold level of 5 and hence, it can be said that there are no issues with respect to collinearity in the indicators causing the formative constructs.

\subsection{Structural model}

Path coefficients or the structural model relationships represent the hypothesized relationships among the constructs and have standardized values between -1 to +1 . To find the significance of a path coefficient, bootstrapping was used at 5000 subsamples (Hair, Hult, Ringle \& Sarstedt, 2016).

Table 2: Hypothesized Path Coefficients

\begin{tabular}{|c|c|c|c|c|}
\hline Hypothesis & $\begin{array}{c}\text { Path coefficients (standard- } \\
\text { ized beta ) }\end{array}$ & T statistics & P values & Decision \\
\hline H1a: $A \rightarrow$ WK & -0.01 & 0.39 & 0.69 & Rejected \\
\hline H1b: $\rightarrow$ WK & 0.10 & 4.19 & 0.00 & Accepted \\
\hline H1c: $\rightarrow$ WK & 0.09 & 3.84 & 0.00 & Accepted \\
\hline H1d: N $\rightarrow$ WK & 0.14 & 6.05 & 0.00 & Accepted \\
\hline H1e: $\mathrm{O} \rightarrow$ WK & 0.00 & 0.11 & 0.90 & Rejected \\
\hline H2: SC $\rightarrow$ WK & 0.27 & 10.62 & 0.00 & Accepted \\
\hline H3: WK $\rightarrow$ CWB & 0.04 & 2.02 & 0.04 & Accepted \\
\hline H4: WK $\rightarrow$ JB & 0.19 & 8.08 & 0.00 & Accepted \\
\hline H5: JB $\rightarrow$ CWB & 0.49 & 24.75 & 0.00 & Accepted \\
\hline
\end{tabular}

Note: $A=$ agreeableness; $C=$ conscientiousness; $E=$ extraversion; $N=$ neuroticism; $\mathrm{O}=$ openness; $\mathrm{SC}=$ social contagion; $\mathrm{WK}=$ workaholism; $\mathrm{JB}=$ job burnout; $\mathrm{p}<0.05$; t>1.96

From the results summarized in Table 2, it can be seen that the traits of agreeableness and openness to experience are not predictors of workaholism. This is evident from their $p$ values of 0.69 and 0.90 respectively. It can be stated that at a $5 \%$ significance level, the hypotheses $\mathrm{H} 1 \mathrm{a}$ and $\mathrm{H}$ 1e did not hold true. On the other hand, the traits of conscientiousness, extraversion, and neuroticism did predict workaholism with $p$ values of 0.00 (each) at $5 \%$ significance level. Moreover, the table also presents the values of path coefficients. It signifies that a change in one unit of the exogenous variable changes the endogenous variable by the size of the path coefficient. In addi- 
tion to this, the structural model path coefficients can be interpreted relative to one another (Hair et al., 2011). Thus, H 1b, H 1c, H 1d had path coefficients of 0.10, 0.09, and 0.14 , respectively. This signifies that neuroticism predicts workaholism the most, that is, $14 \%$. This is followed by conscientiousness and lastly, extraversion. Likewise, a one unit change in conscientiousness, extraversion, and neuroticism would bring a change of $10 \%, 9 \%$ and $14 \%$ in the workaholism, respectively.

The second hypothesis of the study (H2) stated that social contagion (SC) is a predictor of workaholism (WK). With a p value of 0.00 , this hypothesis was accepted. It was also hypothesized (H3) that workaholism (WK) will be a predictor of counterproductive work behavior (CWB) in the organization. This hypothesis was accepted as evident from its $p$ value of 0.04 again at 5\% significance level. Next, hypothesis $\mathrm{H} 4$ stated that job burnout (JB) will also be predicted by workaholism (WK). This hypothesis was also significant with 0.00 p value. Lastly, it was also hypothesized (H5) that employees experiencing job burnout (JB) will be a predictor of counterproductive work behavior (CWB). From Table 2, it can be seen that $\mathrm{H} 5$ was accepted with a $p$ value of 0.00 .

\subsubsection{Indirect effect}

In the present research, job burnout was studied as the mediator between the relationship of workaholism and counterproductive work behavior (H6). To test this mediation, the technique proposed by Zhao, Lynch, and Chen (2010) was used. The result of the mediation effect is presented in Table 3. From the table, it can be seen that the indirect path between workaholism (WK) and counterproductive work behavior (CWB) is significant with a $p$ value of 0.00 at a significance level of $5 \%$ and $t$ statistic of 7.73. In such a scenario where both the indirect effects as well as the direct effects are significant and pointing in the same direction (that is both effects have positive path coefficients), the mediation is said to be complementary mediation. This mediation type overlaps with Baron and Kenny's (1986) partial mediation (Zhao et al., 2010).

Table 3: Hypothesized Path Coefficients - Indirect Effect

\begin{tabular}{|c|c|c|c|c|}
\hline Hypothesis & Path coefficient (standardized beta ) & T statistics & P values & Decision \\
\hline $\begin{array}{c}\text { H6: WK- CWB } \\
\text { (indirect effect) }\end{array}$ & 0.09 & 7.73 & 0.00 & Accepted \\
\hline
\end{tabular}

Note: $\mathrm{p}<0.05 ; \mathrm{t}>1.96$

\subsubsection{Coefficient of determination ( $R^{2}$ value)}

In-sample predictive power was measured through the coefficient of determination $\mathrm{R}^{2}$ (Sarstedt, Ringle, Henseler \& Hair, 2014). 
Table 4: Coefficient of Determination ( $\mathrm{R}^{2}$ Values)

\begin{tabular}{|c|c|}
\hline Endogenous latent variables & $\mathrm{R}^{2}$ values \\
\hline Workaholism & 0.18 \\
\hline Counterproductive work behavior & 0.25 \\
\hline Job burnout & 0.04 \\
\hline
\end{tabular}

From Table 4, it can be seen that big 5 personality traits and social contagion predict $18 \%(0.18)$ of the variance in workaholism. Similarly, workaholism and job burnout predict $25 \%(0.25)$ of the variance in counterproductive work behavior. Lastly, workaholism predicts only $4 \%$ (0.04) variation in job burnout.

\subsubsection{Effect size $\left(f^{2}\right)$}

Using the formula provided by Hair et al. (2016) the effect size $\mathrm{f}^{2}$ was obtained. It measures the change in the value of $\mathrm{R}^{2}$ when a specific exogenous construct is omitted from the model.

\section{$\mathrm{f}^{2}=\mathrm{R}^{2}$ included $-\mathrm{R}^{2}$ excluded $/ 1-\mathrm{R}^{2}$ included}

Effect size $\mathrm{f}^{2}$ values of $0.02,0.15$ and 0.35 indicate small, medium and large effects, respectively (Cohen, 1988). Table 5 summarizes the effect size $\mathrm{f}^{2}$.

Table 5: Effect Size $\mathrm{f}^{2}$

\begin{tabular}{|c|c|c|c|}
\hline Exogenous latent variables & Workaholism & Counterproductive WB & Job Burnout \\
\hline Agreeableness & 0.00 & & \\
\hline Conscientiousness & 0.02 & & \\
\hline Extraversion & 0.02 & & \\
\hline Neuroticism & 0.02 & & \\
\hline Openness & 0.00 & & \\
\hline Social Contagion & 0.07 & & \\
\hline Job Burnout & & & 0.04 \\
\hline Workaholism & & 0.00 & \\
\hline
\end{tabular}

The exogenous latent variables are presented in the first column whereas the first row contains the endogenous variables. From the threshold values provided by Cohen (1988), it can be seen that conscientiousness, extraversion, and neuroticism have a small size effect on workaholism. On the other hand, social contagion also has a small size effect on workaholism which is 0.07 . Moving on to the endogenous construct counterproductive work behavior it can be seen that this variable has two 
predecessors- workaholism and job burnout. Workaholism has no effect on the variable counterproductive work behavior but job burnout has a medium-size effect on counterproductive work behavior with an $\mathrm{f}^{2}$ value of 0.31 . Finally, workaholism has a small size effect on job burnout as it indicated by the effect size of 0.04 .

\subsubsection{Blindfolding and predictive relevance $\mathrm{Q}^{2}$}

Using the blindfolding technique the predictive relevance $\mathrm{Q}^{2}$ was obtained. Blindfolding is an iterative sample reuse technique. A value of $Q^{2}$ greater than 0 affirms the predictive relevance of a specific construct.

The values for $\mathrm{Q}^{2}$ are shown in Table 6. It can be seen that the $\mathrm{Q}^{2}$ values for all three endogenous variables are above 0 which indicates that the model has predictive relevance. In other words, the exogenous constructs are able to predict the indicators of the endogenous variables.

Table 6: Predictive Relevance $Q^{2}$

\begin{tabular}{|c|c|}
\hline Endogenous latent variables & $\mathrm{Q}^{2}$ values \\
\hline Workaholism & 0.17 \\
\hline Counterproductive work behavior & 0.25 \\
\hline Job burnout & 0.03 \\
\hline
\end{tabular}

\section{Discussion and Conclusion}

The results revealed that the traits of agreeableness and openness to experience were not significant predictors of workaholism in the current population. Referring to the work of Van Beek, Taris, Schaufeli, and Brenninkmeijer (2013) the possibility of these two traits being associated with work engagement cannot be eliminated. While, individuals open to experience are also open to learning in order to develop themselves, agreeableness, on the other hand, is linked with a lack of stress. They also lack the urge to control situations (Little, Lecci \& Watkinson, 1992), hence, supporting the findings of this study.

On the contrary, the significant association of the traits of neuroticism and extraversion with workaholism is in accordance with the results of Andreassen et al. (2010) and Aziz and Tronzo (2011), respectively. Neuroticism has been linked with exhibiting anxiety (John, 1990) and there is enough empirical support to conclude that psychiatric disorders in the form of anxiety have been linked to workaholism (Lieb, 2015). Congruently, individuals possessing the trait of extraversion tend to be dominant. It is possible that they indulge in excessive work in form of workaholism in order to maintain their dominance over their colleagues (John, 1990). 
Correspondingly, as identified by Clark et al. (1996) individuals with a high level of conscientiousness tend to be more performance oriented and hence, workaholics. Conscientious individuals are also achievement-oriented and therefore, keen on performing well (Chamorro-Premuzic \& Furnham, 2008). This notion lends support to the findings of this study.

On the other hand, the rationale behind a significant association of social contagion with workaholism can be attributed to the fact that individuals indulging in social comparisons on work would like to improve and/or restore their feelings of self-esteem for the sake of enhancing one's self (Campbell, 1990).

Another interesting finding of this study was workaholism leading to CWB in the workplace which strengthened the notion that it is considered as the bad type of working hard (Shimazu \& Schaufeli, 2009). Being low on subjective well-being, workaholics tend to experience frequent anger and anxiety bouts (Schaufeli et al., 2009a). This eventually causes accumulation of stress which is vented out in the form of job burnout (Fritz \& Sonnentag, 2006).

To sum up, by defining and measuring workaholism in an addiction framework, it can be established that social contagion is the stronger predictor of workaholism followed by the personality traits of neuroticism. Also, the view that workaholism may have negative repercussion(s) can be further strengthened by the fact that workaholism leads to counterproductive work behaviors and is mediated by the presence of job burnout. However, this mediation proved to be complementary. This reinforces the prognostication of workaholism as an addiction.

The findings from this study are unique in itself. Some of the previous studies undertaken on workaholism in Pakistan involved small sample sizes. For example, in a study conducted by Khan and Shah (2016) the sample consisted of 65 employees working in the non-governmental organizations of one particular city. Although the findings did reveal the finance department to have a majority of the workaholics followed by the human resource department, the low sample size renders it difficult to generalize results. Similarly, in another study by Mir and Kamal (2018) the population was heterogeneous where less than 100 university teachers were targeted. In a study by Sahar and Waqar (2014) conducted in the corporate world showed that employees working in the banking sector were more workaholic than telecom sector employees. They also found a positive relationship between workaholism and psychological well-being. These statistics indicate that research within the academia as a white-collar profession was previously neglected. 


\section{Practical Implications and Future Research}

To counter the happening of negative practices first and foremost the organizations need to adopt a preventive approach towards curbing workaholism. In this regard, it is well advised that a climate that endorses and fosters employee growth be favored in order to discourage the employees to indulge in overwork to the extent that it becomes the bad type of working hard (workaholism).

From the literature, in general, it is known that social comparisons can harm trust (Dunn, Ruedy, Schweitzer, 2012). Therefore, it is suggested that an environment where trust prevails should be fostered. This would be indicative of the fact that the institution values the growth and development of its faculty. The institutions must constantly work on devising class load in such a way that there is some sort of a balance, and favors aren't given to anybody due to seniority, experience or long tenure.

The organization should also be a source of social support for those who are workaholics. Of the many advantages social support offers, it will also enable them to deal with routine challenges wisely. In addition, the prevention of acts of aggression, in the form of CWB, can also be done by emphasizing the institutions' ethical climate.

Future research is encouraged to find out the effects of workaholics on co-workers. Another appealing implication could be to use peer ratings of co-workers to assess workaholism and the effect it has on the lives of workaholics.

\section{Limitations of the Study}

One of the limitations of the study was the assessment of model fit indices. As the aim of this study did not include a comparison between different models based on a priori theory, so achieving model fit was not an issue in this case. Another possible limitation of the study was the use of a shorter version of the big five traits. Lastly, the questionnaires were distributed to the respondents while they were on the job. This enhances the need for a relaxed setting so that the full concentration of the respondents can be assured.

\section{References}

Andreassen, C. S., Griffiths, M. D., Gjertsen, S. R., Krossbakken, E., Kvam, S., \& Pallesen, S. (2013). The relationships between behavioral addictions and the five-factor model of personality. Journal of Behavioral Addictions, 2(2), 90-99.

Andreassen, C. S., Hetland, J., \& Pallesen, S. (2010). The relationship between workaholism, basic needs satisfaction at work and personality. European Journal of Personality, 24, 3 - 17. 
Andreassen, C. S., Torsheim, T., Brunborg, G. S., \& Pallesen, S. (2012). Development of a Facebook addiction scale. Psychological Reports, 110(2), 501-517.

Aziz, S., \& Tronzo, C. L. (2011). Exploring the relationship between workaholism facets and personality traits: A replication in American workers. The Psychological Record, 61, 269-286.

Bakker, A. B., Van Der Zee, K. I., Lewig, K. A., \& Dollard, M. F. (2006). The relationship between the big five personality factors and burnout: A study among volunteer counselors. The Journal of Social Psychology, 146, 31-50.

Balducci, C., Cecchin, M., Fraccaroli, F., \& Schaufeli, W. B. (2012). Exploring the relationship between workaholism and workplace aggressive behavior: The role of job-related emotion. Personality and Individual Differences, 53, 629-634.

Barling, J., Dupre, K. E., \& Kelloway, E. K. (2009). Predicting workplace aggression and violence. Annual Review of Psychology, 60, 671-692.

Baron, R. M., \& Kenny, D. A. (1986). The moderator-mediator variable distinction in social psychological research: Conceptual, strategic, and statistical considerations. Journal of Personality and Social Psychology, 51, 1173-1182.

Benabou, R., \& Tirole, J. (2004). Willpower and personal rules. Journal of Political Economy, 112, 848 - 86.

Bennett, R. J., \& Robinson, S. L. (2000). Development of a measure of workplace deviance. Journal of Applied Psychology, 85, 349 - 360.

Bentley, P. J., \& Kyvik, S. (2012). High Educ, 63(4), 529-547. doi: https://doi.org/10.1007/s10734011-9457-4

Bianchi, A., \& Phillips, J. G. (2005). Psychological predictors of problem mobile phone use. Cyber Psychology $\mathcal{E}$ Behaviour, 8(1), 39-51.

Brett, J.M., \& Stroh, L.K. (2003). Working 61 plus hours a week: Why do managers do it? Journal of Applied Psychology, 88(1), 67-78.

Bruck, C. S., \& Allen, T. D. (2003). The relationship between big five personality traits, negative affectivity, type A behavior and work-family conflict. Journal of Vocational Behaviour, 63(3), 457-472.

Buhler, K. E., \& Land, T. (2003). Burnout and personality in intensive care: an empirical study. Hospital Topics, 81(4), 5-12.

Burke, R. J. (2008). Work motivations, satisfactions, and health: Passion versus addiction. In R. Burke, \& C. L. Cooper (Eds.), The long working hours culture. Causes, consequences and choices (pp. 227-251). Bingley, UK: Emerald.

Burke, R. J., Matthiesen, S. B., \& Pallesen, S. (2006). Personality correlates of workaholism. Personality and Individual Differences, 40, 1223 - 1233. 
Campbell, J. D. (1990). Self-esteem and the clarity of the self-concept. Journal of Personality and Social Psychology, 59, 538 - 549.

Chamorro-Premuzic, T., \& Furnham, A. (2008). Personality, intelligence and approaches to learning as predictors of academic performance. Personality and Individual Differences, 44, 1596 - 1603.

Chin, W. W. (2010). How to write up and report PLS analyses. In V. E. Vinzi, W. W. Chin, J. Henseler, \& H. Wang (Eds.), Handbook of partial least squares: Concepts, methods and applications in marketing and related fields (pp. 655-690). Berlin: Springer.

Clark, L. A., Livesley, W. J., Schroeder, J. L., \& Irish, S. L. (1996). Convergence of two systems for assessing specific traits of personality disorder. Psychological Assessment, 8, 294-303.

Cohen, J. (1988). Statistical power analysis for the behavioral sciences. Hillsdale, New Jersey: Lawrence Erlbaum Associates.

Cordes, C. L., \& Dougherty, T. W. (1993). A review and an integration of research on job burnout. The Academy of Management Review, 18(4), 621 - 656.

Correa, T., Hinsley, A. W., \& De Zuniga, H. G. (2010). Who interacts on the Web?: The intersection of users' personality and social media use. Computers in Human Behaviour, 26(2), 247-253.

Costa, P. T., \& McCrae, R. R. (1987). Neuroticism, somatic complaints, and disease: Is the bark worse than the bite? Journal of Personality, 55, 299-316.

Costa, P. T., \& McCrae, R. R. (1991). Revised NEO personality inventory (NEO PI-R) and NEO five factor inventory (NEO-FFI): Professional Manual. Odessa, FL: Psychological Assessment Resources.

Costa, P. T., Jr., \& McCrae, R. R. (1992). Normal personality assessment in clinical practice: The NEO personality inventory. Psychological Assessment, 4, 5-13.

De Vries, M. F. R. K. (2005). The dangers of feeling like a fake. Harvard Business Review, 83(9), 108.

Dunn, J., Ruedy, N. E., \& Schweitzer, M. E. (2012). It hurts both ways: How social comparisons harm affective and cognitive trust. Organizational Behaviour and human Decision Processes, 117, 2 - 14.

Ellis, A. (1994). Reason and emotion in psychotherapy. Secaucus, NJ: Carol Publishing Group.

Epstein, S. (1994). Integration of the cognitive and the psychodynamic unconscious. American Psychologist, 49(8), 709-724.

Eysenck, H. J. (1967). Intelligence assessment: A theoretical and experimental approach. British Journal of Educational Psychology, 37(1), 81-98.

Eysenck, H. J. (1997). Addiction, personality and motivation. Human Psychopharmacology. Human Psychopharmacology, 12, 579-587.

Festinger, L. (1954). The theory of social comparison processes. Human Relations, 7, 117 - 140. doi: 10.1177/001872675400700202. 
Fornell, C., \& Larcker, D.F. (1981). Evaluating Structural Equation Models with Unobservable Variables and Measurement Error. Journal of Marketing Research, 18(1), 39-50.

Freudenberger, H. J. (1983). Burnout: Contemporary issues, trends, and concerns. In B. A. Farber (Ed.), Stress and burnout in the human service professions (pp. 23-28). New York: Pergamon.

Fritz, C., \& Sonnentag, S. (2006). Recovery, well-being, and performance-related outcomes: The role of workload and vacation experiences. Journal of Applied Psychology, 91, 936 - 945.

Gibbons, F. X., \& Buunk, B. P. (1999). Individual differences in social comparison: Development of a scale of social comparison orientation. Journal of Personality and Social Psychology, 76(1), 129-142.

Gold, A. H., Malhotra, A., \& Segars, A. H. (2001). Knowledge management: An organizational capabilities perspective. Journal of Management Information Systems, 18(1), 185-214.

Gjerde, P. F., \& Cardilla, K. (2009). Developmental implications of openness to experience in preschool children: Gender differences in young adulthood. Developmental Psychology, 45(5), 1455.

Glaser, R. (1976). Components of a psychology of instruction: Toward a science of design. Review of educational research, 46(1), 1-24.

Gold, A. H., Malhotra, A., \& Segars, A. H. (2001). Knowledge management: An organizational capabilities perspective. Journal of Management Information Systems, 18(1), 185 - 214.

Goldberg, L. R. (1990). An alternative description of personality: The big five-factor structure. Journal of Personality and Social Psychology, 59, 1215-1229.

Golembiewski, R. T., Boudreau, R. A., Sun, B. C., \& Luo, H. (1998). Estimates of burnout in public agencies: worldwide, how many employees have which degrees of burnout, and with what consequences? Public Administration Review, 58(1), 59-65.

Grant, J. E., Potenza, M. N., Weinstein, A., \& Gorelick, D. A. (2010). Introduction to behavioral addictions. The American Journal of Drug and Alcohol Abuse, 36(5), 233-241.

Griffiths, M. (1996). Behavioral addiction: an issue for everybody? Employee Counselling Today, 8(3), 19-25.

Hair, J. F., Hult, G. T.M., Ringle, C.M., \& Sarstedt, M. (2016). A primer on partial least squares structural equation modeling (PLS-SEM) (2nd ed.). Thousand Oaks, CA: Sage.

Hair, J. F., Ringle, C. M., \& Sarstedt, M. (2011). PLS-SEM: Indeed a silver bullet. Journal of Marketing Theory and Practice, 19(2), 139-150.

Henseler, J., Ringle, C. M., \& Sinkovics, R. R. (2009). The use of partial last squares path modeling in international marketing. Advances in International Marketing, 20, 277-319.

Hill, S. Y., Shen, S., Lowers, L., \& Locke, J. (2000). Factors predicting the onset of adolescent drinking in families at high risk for developing alcoholism. Biological Psychiatry, 48(4), 265-275.

Hobfoll, S. E. (1989). Conservation of resources: A new attempt at conceptualizing stress. American 
Psychologist, 44, 513-524.

Hobfoll, S. E., \& Shirom, A. (2001). Conservation of resources theory: Applications to stress and management in the workplace. In R. T. Golembiewski (Ed.), Handbook of organization behavior (pp. 57-81). New York: Dekker.

Horne, J. (1998). Understanding leisure time and leisure space in contemporary Japanese society. Leisure Studies, 17, $37-52$.

Hu, Q., Schaufeli, W. B., Taris, T. W., Hessen, D. J., Hakanen, J., Salanova, M., \& Shimazu, A. (2014). East is east and west is west and never the twain shall meet: Work engagement and workaholism across eastern and western cultures. Journal of Behavioural and Social Sciences, 1, 6 - 24.

Jacobs, J. A. (2004). The faculty time divide. Sociological Forum, 19(1), 3 - 27.

Jacobs, J. A., \& Winslow, S. E. (2004a). Overworked Faculty: Job Stresses and Family Demands. The Annals of the American Academy of Political and Social Science, 596(1), 104 - 129. doi: https://doi. org $/ 10.1177 / 0002716204268185$

Jacobs, J. A., \& Winslow, S. E. (2004b). The academic life course, time pressures and gender inequality. Community, Work E Family, 7(2), 143 - 161. doi: https://doi.org/10.1080/1366880042000245443

Jarvis, C.B., Mackenzie, S.B., \& Podsakoff, P.M. (2003). A critical review of construct indicators and measurement model misspecification in marketing and consumer research. Journal of Consumer Research, 30(2), 199-218.

John, O. P. (1990). The big five factor taxonomy: Dimensions of personality in the natural language and in questionnaires. In L. A. Pervin \& O. P. John (Eds.), Handbook of personality: Theory and research (2nd ed., pp. 66-100). New York: Guildford Press.

John, O. P., Donahue, E. M., \& Kentle, R. L. (1991). The big five inventory - versions $4 a$ and 54. Berkeley, CA: University of California, Berkeley, Institute of Personality and Social Research.

Khan, S., \& Shah, M. H. (2016). Workaholism: Reasons, influences and objective assessment of Ngo employees in Peshawar. City University Research Journal, 6(1), 37 - 47.

Krischer, M. M., Penney, L. M., \& Hunter, E. M. (2010). Can counterproductive work behaviors be productive? CWB as emotion-focused coping. Journal of occupational health psychology, 15(2), 154.

Latane, B. (2000). Pressures to uniformity and the evolution of cultural norms: Modelling dynamic social impact. In D. R. Ilgen, \& C. L. Hulin (Eds.), Computational modeling in organizations. Washington, D.C: The American Psychological Association.

Lazarus, R.S. (1991). Emotion and Adaptation. New York: Oxford Univ. Press

Le Bon, G. (1903). The crowd: A study of the popular mind. London: T. Fisher Unwin.

Lieb, R. (2015). Epidemiological perspectives on co-morbidity between substance use disorders and other 
mental disorders. In G. Dom \& F. Moggi (Eds.), Co-Occurring addictive and psychiatric disorders (pp. 3-12). Berlin: Springer.

Little, B. R., Lecci, L., \& Watkinson, B. (1992). Personality and personal projects: Linking the big five and PAC units of analysis. Journal of Personality, 60 (2), 501 - 525.

MacKenzie, S. B., Podsakoff, P.M., \& Jarvis, C.B. (2005). The problem of measurement model misspecification in behavioral and organizational research and some recommended solutions. Journal of Applied Psychology, 90(4), 710-730.

Maslach, C. (1986). Stress, burnout and workaholism. In R. R. Killberg, \& R. W. Thoreson (Eds.), Professionals in distress: Issues, syndromes and solutions in psychology (pp. 53-73). Washington, DC: American Psychological Association.

Maslach, C., \& Jackson, S. E. (1981). The measurement of experienced burnout. J. Occup. Behav, 2, $99-113$.

Maslach, C., Jackson, S. E., \& Leiter, M. P. (1996). MBI: Maslach burnout inventory. Sunnyvale (CA): $\mathrm{CPP}$, Incorporated.

McCrae, R. R., \& Costa, P. T. (1986). Personality, coping, and coping effectiveness in an adult sample. Journal of Personality, 54, 385 - 405.

McMillan, L. H., \& O’Driscoll, M. P. (2004). Workaholism and health: Implications for organizations. Journal of Organizational Change Management, 17(5), 509 - 520.

McMillan, L. H., O’Driscoll, M. P., \& Burke, R. J. (2003). Workaholism: A review of theory, research and new directions. In C. L. Cooper, \& I. T. Robertson (Eds.), International review of industrial and organizational psychology (pp. 167-190). New York: John Wiley.

Meyer, J. W., Ramirez, F. O., Frank, D. J., \& Schofer, E. (2007). Higher Education as an Institution. In P. J. Gumport (Ed.), Sociology of higher education: Contributions and their contexts (pp. 187 - 221). Baltimore: John Hopkins University Press.

Mir, I., \& Kamal, A. (2018). Role of workaholism and self-Concept in predicting impostor feelings among employees. Pakistan Journal of Psychological Research, 33(2), 413 - 427.

Mudrack, P. E. (2004). Job involvement, obsessive-compulsive personality traits, and workaholic behavioral tendencies. Journal of Organizational Change Management, 17, 490-508.

Naughton, T. J. (1987). A conceptual view of workaholism and implications for career counseling and research. The Career Development Quarterly, 35, 180 - 187.

Neuman, J. H., \& Baron, R. A. (2005). Aggression in the workplace: A social psychological perspective. In S. Fox, \& P. E. Spector (Eds.), Counterproductive work behavior (pp. 13-40). Washington, DC: American Psychological Association.

Oates, W. (1971). Confessions of a workaholic: The facts about work addiction. New York: World 
Publishing.

Penney, L. M., \& Spector, P. E. (2007). Emotions and counterproductive work behavior. In N. M. Ashkanasy \& C. L. Cooper (Eds.), Research companion to emotion in organizations (pp. 183-196). Northampton, MA: Edward Elgar Publishing.

Penney, L.M., Hunter, E. M., \& Perry, S. J (2011). Personality and counterproductive work behavior: Using conservation of resources theory to narrow the profile of deviant employees. Journal of Occupational and Organizational Psychology, 84, 58-77.

Porter, G. (1996). Organizational impact of workaholism: Suggestions for researching the negative outcomes of excessive work. Journal of Occupational Health Psychology, 1, 70 - 84. doi: 10.1037/10768998.1.1.70

Redl, F. (1949). The phenomenon of contagion and shock effect in group therapy.

Robinson, B. (1999). The work addiction risk test: Development of a tentative measure of workaholism. Perceptual $\mathbb{E}$ Motor Skills, 88, 199 - 210.

Robinson, B.E. (2001). Workaholism and family functioning: A profile of familial relationships, psychological outcomes and research considerations. Contemporary Family Therapy, 23(1), 123-135.

Robinson, S., \& Bennett, R. (1995). A typology of deviant workplace behaviors: A multi-dimensional scaling study. Academy of Management Journal, 42(1), 100 - 108.

Ross, C., Orr, E. S., Sisic, M., Arseneault, J. M., Simmering, M. G., \& Orr, R. R. (2009). Personality and motivations associated with Facebook use. Computers in Human Behaviour, 25(2), 578-586.

Sahar, W., \& Waqar, S. (2014). Workaholism and psychological well-being among employees of banking and telecom sector. Case Studies journal, 3(10), 12 - 29.

Sarstedt, M., Ringle, C. M., Henseler, J., \& Hair, J. F. (2014). On the emancipation of PLS-SEM: A commentary on Rigdon (2012). Long Range Planning, 47(3), 154-160.

Schaufeli, W. B., Bakker, A. B., Van der Heijden, F. M., \& Prins, J. T. (2009b). Workaholism, burnout and well-being among junior doctors: The mediating role of role conflict. Work $\mathcal{E}$ Stress, 23, 155 - 172.

Schaufeli, W. B., Shimazu, A., \& Taris, T. W. (2009a). Being driven to work excessively hard: The evaluation of a two-factor measure of workaholism in the Netherlands and Japan. Cross-Cultural Research, 43(4), 320 - 348.

Schaufeli, W. B., Taris, T. W., \& Bakker, A. B. (2006). Dr. Jekyll or Mr. Hyde? On the differences between work engagement and workaholism. In R. J. Burke, Research companion to working time and work addiction (pp. 193 - 217). Edward Elgar: Cheltenham.

Shimazu, A., \& Schaufeli, W. B. (2009). Is workaholism good or bad for employee well-being? The distinctiveness of workaholism and work engagement among Japanese employees. Industrial Health, $47,495-502$. 
Shimazu, A., Schaufeli, W. B., \& Taris, T. W. (2010). How does workaholism affect worker health and performance? The mediating role of coping. International Journal of Behavioural Medicine, 17, 154 - 160.

Siebert, S. E., \& Kraimer, M. L. (2001). The five-factor model of personality and career success. Journal of Vocational Behaviour, 58, 1 - 21.

Spector, P. E., \& Fox, S. (2005). The stressor-emotion model of counterproductive work behavior. In S. Fox, \& P. E. Spector (Eds.), Counterproductive work behavior (pp. 151 - 174). Washington, DC: American Psychological Association.

Spector, P. E., Fox, S., \& Domagalski, T. A. (2006). Emotions, violence and counterproductive work behavior. In E. K. Kelloway, J. Barling, \& J. Hurrell (Eds.), Handbook of workplace violence (pp. 29 -46). Thousand Oaks, CA: Sage.

Sussman, S. (2012). Workaholism: A review. Journal of Addiction Research and therapy, 6(1), 1 - 10.

Taris, T. W., Schaufeli, W. B., \& Verhoeven, L. C. (2005). Workaholism in the Netherlands: Measurement and implications for job strain and work-nonwork conflict. Applied Psychology: An International Review, 54(1), 37 - 60 .

Tsai, H. F., Cheng, S. H., Yeh, T. L., Shih, C. C., Chen, K. C., Yang, Y. C., \& Yang, Y. K. (2009). The risk factors of Internet addiction-a survey of university freshmen. Psychiatry Research, 167(3), 294-299.

Tziner, A., \& Tanami M. (2013). Examining the links between attachment, perfectionism, and job motivation potential with job engagement and workaholism. Journal of Work and Organizational Psychology, 29, 65 - 74 .

Ugander, J., Backstrom, L., Marlow, C., \& Kleinberg, J. (2012). Structural diversity in social contagion. Proceedings of the National Academy of Sciences, 201116502.

Ugwu, F. O. (2011). Building workaholic behavior in organizations: The role of organizational trust and psychological empowerment. Nigeria Journal of Psychological Research, 7, 10 - 24.

Van Beek, I., Taris, T., Schaufeli, W. B., \& Brenninkmeijer, V. (2013). Heavy work investment: Its motivational make-up and outcomes. Journal of Managerial Psychology, 29(1), 46 - 62.

Walker, M. B. (1989). Some problems with the concept of gambling addiction: Should theories of addiction be generalized to include excessive gambling? Journal of Gambling Behaviour, 5(3), 179-200.

Watson, D., \& Hubbard, B. (1996). Adaptational style and dispositional structure: Coping in the context of the five-factor model. Journal of Personality, 64, 737 - 774.

Werts, C. E., Linn, R. L., \& Joreskog, K. G. (1974). Intraclass reliability estimates: Testing structural assumptions. Educational and Psychological Measurement, 34, 25-33.

Williamson, I. O., \& Cable, D. M. (2003). Organizational hiring patterns, interfirm network ties, and inter-organizational imitation. Academy of Management Journal, 46(3), 349-358.

Yamane, T. (1967). Statistics; An Introductory Analysis (2nd ed.). New York: Harper and Row.

Zhao, X., Lynch Jr.,J. G., \& Chen, Q. (2010). Reconsidering Baron and Kenny: Myths and truths about mediation analysis. The Journal of Consumer Research, 37(2), 197-206. 